\title{
Seeking Out the Spaces Between: Using Improvisation in Collaborative Composition with Interactive Technology
}

\author{
Sarah Nicolls
}

I

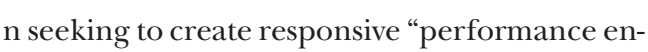
vironments" at the piano, I explore live, performative control of electronics to create better connections for both performer (providing the same level of interpretive freedom as with a "pure" instrumental performance) and audience (communicating clearly to them). I have been lucky to witness first-hand many live interactive performances and to work with various empathetic composers/performers in flexible working environments. Collaborating with experienced technologists and musicians, I have witnessed time and again what, for me, is a fundamental truth in interactive instrumental performance: As a living, spontaneous form it must be nurtured and informed by the performer's physicality and imagination as much as by the creativity or knowledge of the composer and/ or technologist.

Specifically in the case of sensors, their dependence on the detail of each person's body and reactions is so refined as to necessitate, I would argue, an entirely collaborative approach and therefore one that involves at least directed improvisation and, more likely, fairly extensive improvised exploration. The fundamentally personal and intimate nature of sensor readings - the amount of tension created by each performer, the shape of the ancillary gestures or the level of emotional involvement (especially relevant when using galvanic skin response or EEG) - makes creating pieces with sensors extremely difficult for a composer to do in isolation. Improvisation therefore provides a way for performer and composer to generate a common musical and gestural language.

Related to these issues is the fact that the technical and notational parameters in interactive music are not yet (and may never be) standardized, thereby creating a very real and practical need for improvisation to figure at least somewhere in the process.

Sarah Nicolls (artist, educator), Centre for Contemporary Music Practice, School of Arts, Brunel University, Kingston Lane, Uxbridge, UB8 3PH, U.K. E-mail: <info@sarahnicolls. com>. Web site: <www.sarahnicolls.com $>$.

See $<$ mitpressjournals.org/lmj/-/20 $>$ and $<$ www.sarahnicolls.com $>$ for supplemental files related to this article.

Co-author on Case Study 1: Richard Barrett, Wilhelm-Stolze-Strasse 30, 10249 Berlin, Germany. E-mail: <richard@furtlogic.com>.

Co-authors on Case Study 4: Samer Abdallah, Kurt Jacobson, Andrew Robertson, Adam Stark and Nick Bryan-Kinns, Centre for Digital Music, Queen Mary, University of London (QMUL), Mile End Road, London E1 4NS, U.K. E-mail: c/o <adam.stark@elec.qmul. ac.uk $>$. Web: $\langle$ http:// www.eecs.qmul.ac.uk/ nickbk $>$.

\section{CONTEXT}

Many practitioners in the field of live performance with electronics make their own interfaces or instruments with which they improvise; this is readily demonstrated by communities such as New Interfaces for Musical Expression (NIME), inspired by leading figures such as Nicolas Collins and Michel Waisvisz. From what is now a hugely broad field, performances I have witnessed recently that seem most relevant, either through their use of physical drama or a particular technology, include Chikashi Miyama ("Angry Sparrow"), in his dazzling, virtuosic and humorous performance on a self-made interface [1], and Derek Holzer [2], whose optical discs are attached to spinning motors and thrust under an overhead projector for instant, rough-and-ready multimedia effect.

Relevant sensor performances include Atau Tanaka (Sensors_Sonics_Sights) (SSS) [3] and Benjamin Knapp [4]; both use the BioMuse sensor system, which was invented by Knapp and Hugh Lusted [5]. Tanaka and Knapp present a fascinating contrast, as they use the same system to quite opposite ends: Tanaka is a highly gestural, physically active and expressive performer, while Knapp performs seated and-using sensors including EEG and galvanic skin response-plays with emotional readings, generating music from a quite inward control of his internal self. At MIT, Elena Jessop developed a beautifully intuitive glove [6], which enables her, for example, to grab notes seemingly from her mouth and lengthen them by pulling away from the face smoothly.

The individuality of each of these performers only strengthens the case that improvisation is not only a way of generating music but also the key to inventing and learning a host of new instruments, interfaces or systems of interaction.

\section{Physicality}

The consideration of physicality is one of the key aspects in creating instrumental performances designed to give control of the electronics to the performer. Several texts affirm the importance of the physicality inherently learnt and absorbed as part of instrumental study. John Richards's article "Lost and Found" [7] has an array of excellent quotations, the most succinct of which is Bob Ostertag's Human Bodies, Computer 
Music: "An intelligence and creativity is actually written into the artist's muscle and bones and blood and skin and hair" [8]. O'Modhrain and Essl make a simiin the experienced musician's understanding of the relationship between action and sound, between performance

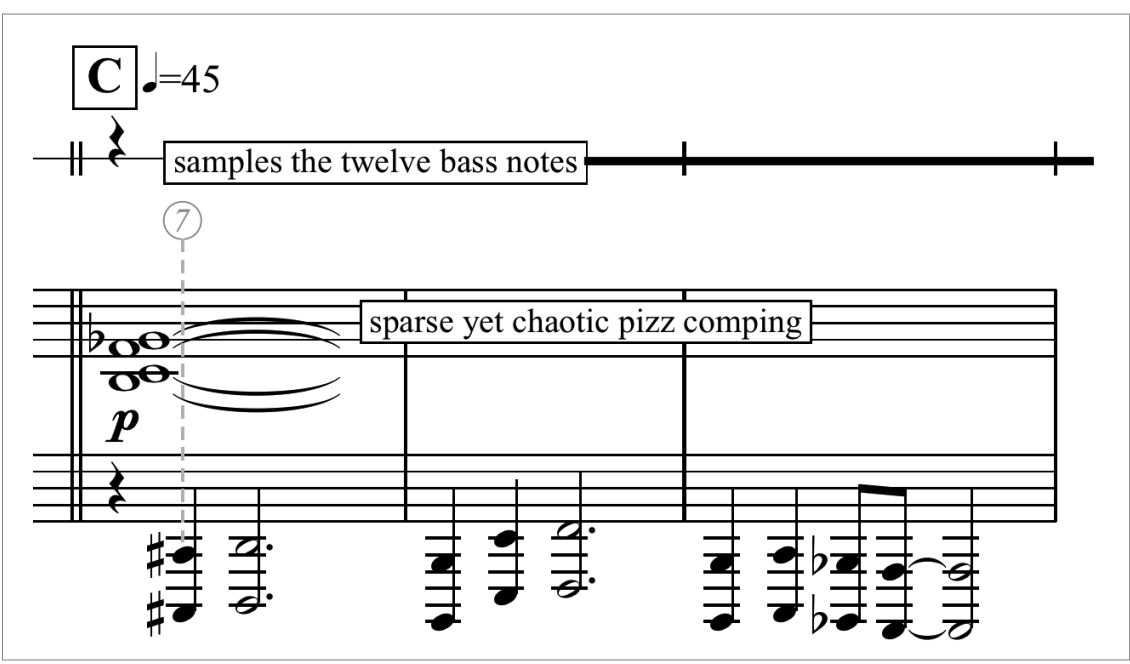

(a)

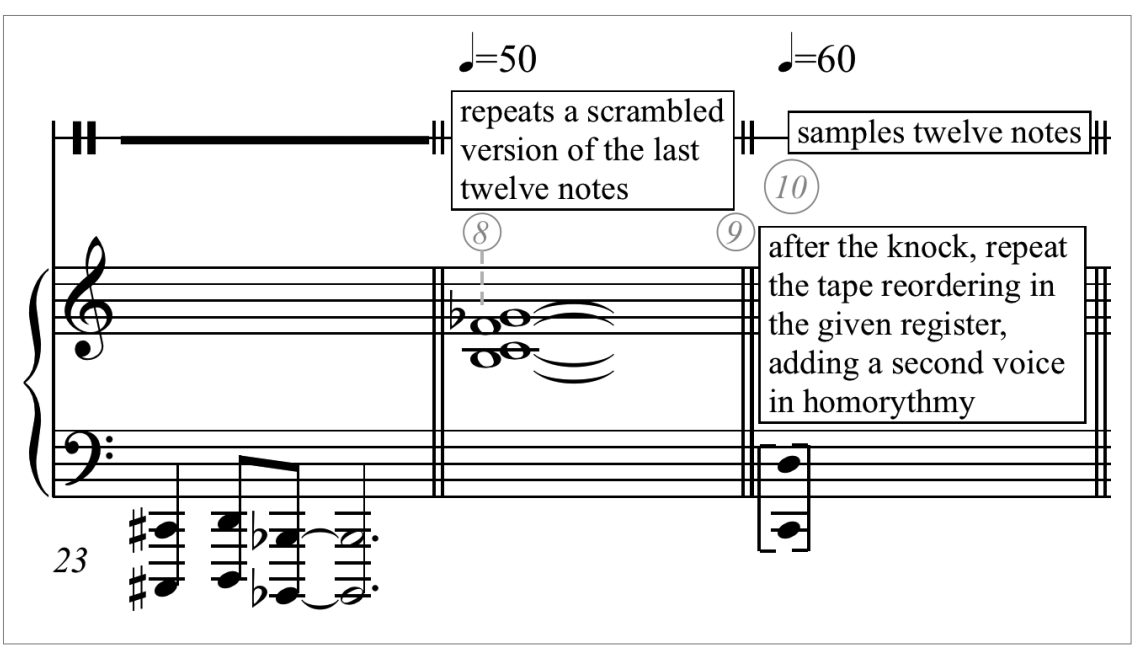

(b) gesture and musical phrase, is a more or less complex internal representation of the dynamics of an instrument" [9]. This notion that there is an imprint of the performer's instrument within the performer's body is vital when considering why improvisation might be necessary in generating the language and parameters for performing interactive instrumental music.

To improvise means at one level to follow one's instinctive urges, the internal reactions and responses that could be referred to as pre-analysis in the performer's own cognitive process. If this is then paired with a physical internal awareness of the capabilities of one's setup or instrument, then the responses will logically be faster and more innate, intuitive and highly responsive than if one or another is non-instinctive. If the performer can intuitively know the edges of physical possibility for the sensors-where the highest and lowest readings are found for example-then the manipulation of these will be managed most deftly.

Instrumentalists have finely tuned systems of tactile or physical feedback (both external, when touching keys etc., and internal-knowing when or how to relax when playing fast, for example) and in working with interactive technology, muscle memory gets built up in a similar way. Also crucial to this discussion: When creating new composed pieces with an interactive setup, to have the performer improvise with the technology means to unlock this inner physical language, to find both what is possible and natural and also what is unnatural, or outside of the natural body language: "the spaces between pianism," in my case. This then allows for the fundamental aesthetic judg-

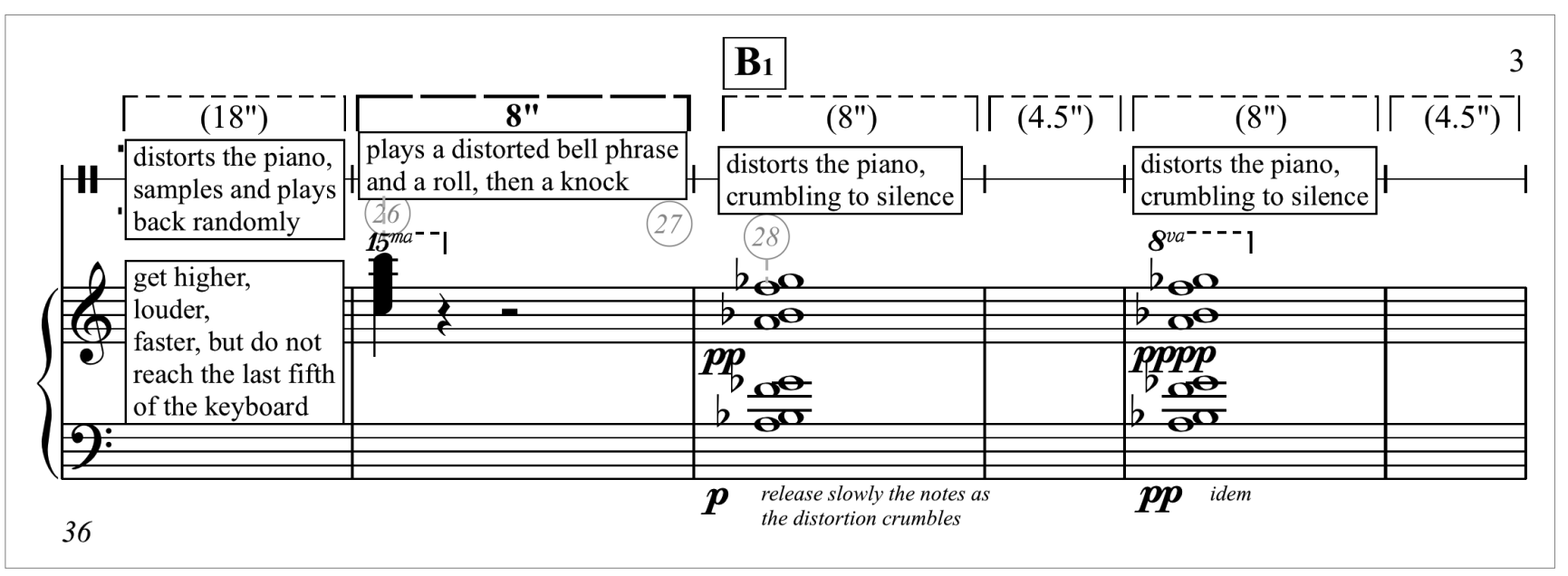

(c)

Fig. 1. Examples of Tremblay's score. (@ Pierre Alexandre Tremblay) 


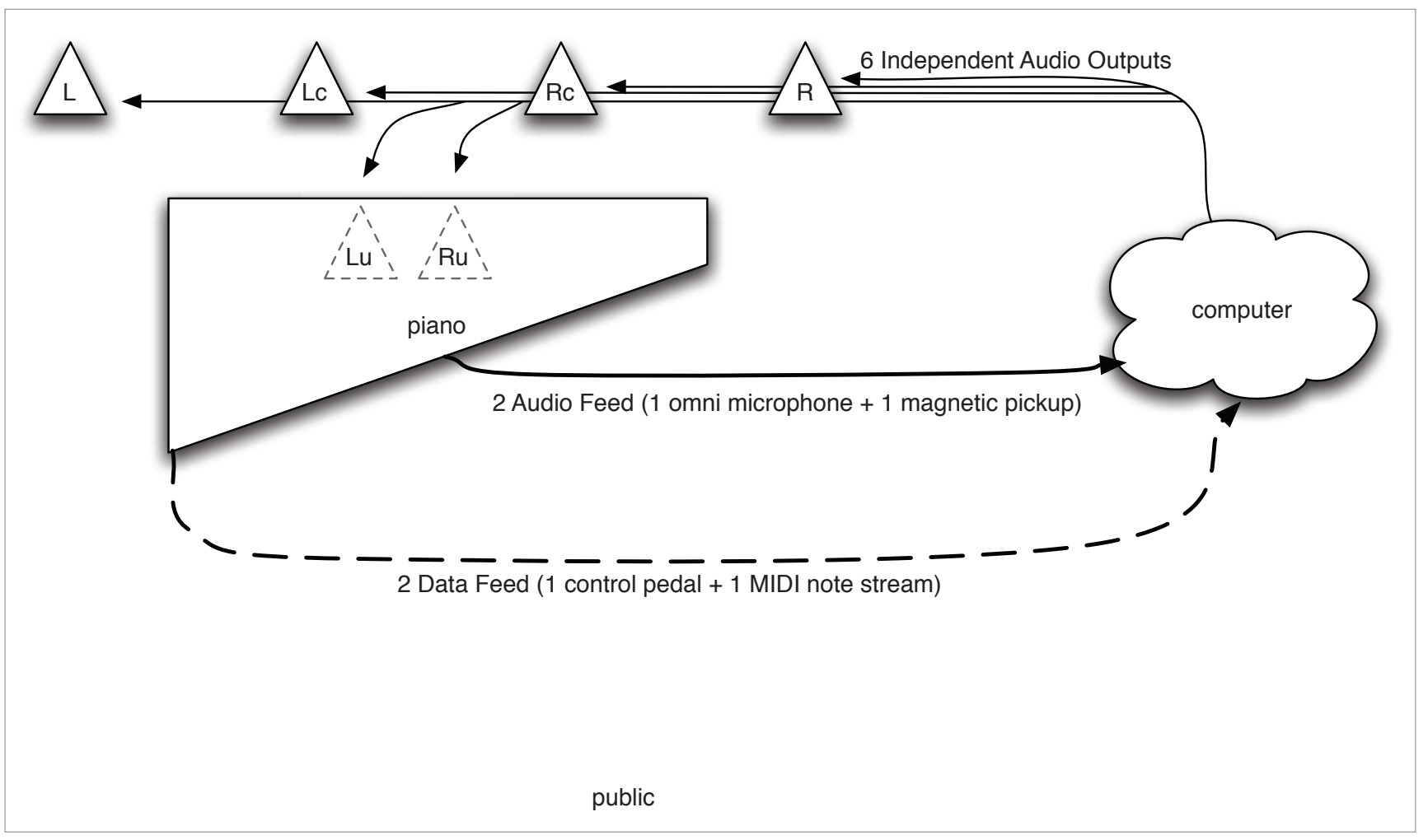

Fig. 2. Tremblay’s schema. (๑ Pierre Alexandre Tremblay)

ment of whether to make the interactive control in addition to, or part of, the instrumental playing.

How the use of physicality may change the original gesture also needs consideration. The writings of Wanderley and Cadoz [10] on this topic are well known; their discussion is furthered by Wanderley and Miranda's extensive 2006 study of new instruments:

The instrumental gesture . . . is applied to a concrete (material) object with which there is physical interaction; specific (physical) phenomena are produced during a physical interaction whose forms and dynamics can be mastered by the subject. These phenomena may become the support for communicational messages and/or be the basis for the production of a material action [11].

The consideration of how adding a sensor to a pianist's arm may affect both the pianist's and the audience's relationships to the original semiotic function of the gesture was one of the main questions resulting from work on Case Study 3. Although not a central issue for this article, I briefly illustrate the problem I found here. Imagine the pianist lifting the arm away from the keyboard, perhaps signifying a breath between musical phrases. When using this gesture to generate data and, in turn, process sound, I found that I would focus on playing the sensors, thereby turning the previously nearly subconscious movement into a material action. As a solo performer is only one body, one mind, these cycles of complexity and confusion perhaps begin to disrupt the artistic spontaneity and intuitive physical sense, potentially undermining the original meaning of the gesture.

\section{Case Study 1}

Richard Barrett's Adrift (2007) was commissioned as part of my first Arts and Humanities Research Council (AHRC)-funded project in 2007 [12], which sought to increase the repertoire for piano and live electronics. I had already performed Barrett's Lost, and this became the foundation for Adrift [13]. Essentially, Adrift amplified Lost into a semi-improvised duet for Barrett and me (with Barrett playing his keyboard system using STEIM'S LiSa program). He began the compositional process by recording my performance of Lost and chopping it into upwards of 70 sections. These were reordered and gradually shifted in pitch, the first ones very slightly, increasing as the piece progressed. The degree of other processes (filtering, short delays and feedback) also generally increased, so that the result gradually diverged in pitch and timbre from the original.

Our pre-made parts (my part: performing the Lost score, and Barrett's part: playing the new recorded version) were now a basis for Adrift, a consistent continuation (into the real time of performance) of the compositional process that gives Lost its particular structure: taking basic material and interpolating more and more inserts into it until the original material becomes almost literally lost in its own extrapolations, distortions, reflections, etc. Either performer in Adrift could interrupt her/his given part at any time and interpolate an improvised passage before continuing from the same point where he/she left off (as if using a pause button).

What was fascinating was how, having ingested Lost through hours of practice, I found myself quite naturally and subconsciously improvising in Barrett's compositional language. Helped by having rehearsed in close proximity over several sessions and having witnessed several performances by Barrett in his groups FURT and fORCH [14], I effectively internalized the physical language that accompanies his music. In the live performance [15], Barrett sat at the other end of the piano, facing me, in the position of a second pianist in a two-piano 
work, and the amplification was local (a stereo pair was placed at either end of the piano). Thus, both of us performed toward each other, creating an intimate mirror image.

Barrett's experience of improvisation within the compositional process has constantly evolved; he wrote the following to me after our collaboration:

The more I attempt to define what improvisation is, the more it seems to slip through the fingers; if, for example, it is defined as those aspects of musical creation which are spontaneous or unplanned, you run into difficulties. So instead, I prefer to think of "composition" as defining the act of bringing music into being, and "improvisation" as one element among various means by which that might be brought about. Thus, it isn't really a matter of bringing "improvisation" and "composition" together, which at first I thought it was: it is more a question of realizing that they aren't really two different things [16].

It is interesting to note that as the pianist, I was able to move from studying Barrett's compositional language to improvising something comparable, while as composer Barrett used improvisation to seek out his compositional language. This cyclical process informed the project and helped to create a fine balance between freedom and a stylized, consistent musical language. Although the interpreter was relatively free, the composer's voice in fact infused all aspects of the music.

\section{CASE STUdy 2}

Pierre Alexandre Tremblay's Un clou, son marteau et le béton (2008) [17] illustrates the use of improvisation in generating material, finding a common and genuinely cumulative language between composer and performer, and creating a long piece of music (around $22 \mathrm{~min}$ utes), which is rigorously composed, yet with only approximately 36 bars of music written on a stave. I had heard La Rage, Tremblay's 50-minute suite for free-jazz drummer and electronics, showing Tremblay's ability to frame a multi-dimensional performer/machine interaction, combining composition and improvisation. Tremblay and I used improvisation from the outset, improvising together at first to get to know each other as musicians, with Tremblay on laptop and bass guitar. We then began the piece using bare-boned notation that I improvised upon to test musical gestures and specific real-time processing. Tremblay also asked me to improvise freely within some settings: over a fixed electronic part, or within some real-time processing that I would subvert with my own musical inputs. We recorded the results to use as triggers for the next session. Tremblay created notation (mixtures of text, conventional and guided improvisation) to show how he would interpret what I had played, which allowed me to feed back on what was communicated to me, building up the most efficient or relevant language for the piece (Fig. 1). This process enabled us to understand each other's perceptive interpretations of symbol, word and sound.

We had several sessions like this, gradually obtaining passages that we could easily re-create through notational shorthand and that could also be understood by someone else coming fresh to the score. Sections of the piece used systematic processes, thereby limiting the need for notation; one example is a section in which the computer and I built up an intensifying call and response, with the computer taking my notes and reordering and speeding them up, and I then imitating its rhythmic profile with new pitches. Other sections used a bias from the background to direct the improvisation subliminally: for instance, a relatively free section with a given fixed electronic part allows imposition of a target on an improviser without explicitly giving musical instructions.

Tremblay then wrote the piece, using either audio control signals (certain audible pitches or the creation or absence of sound) or direct inputs (we used the PianoBar-a MIDI device placed over the keys of the piano, reading the pitch and velocity of each key when played) (Fig. 2). Because the piece used different input messages (for example, depressing keys or making vocal noises) to the patch at different points in the piece, it felt highly responsive in performance: It

Fig. 3. Atau Tanaka wearing the EMG sensors in the positions we used. (Photo $\subset$ Sarah Nicolls)

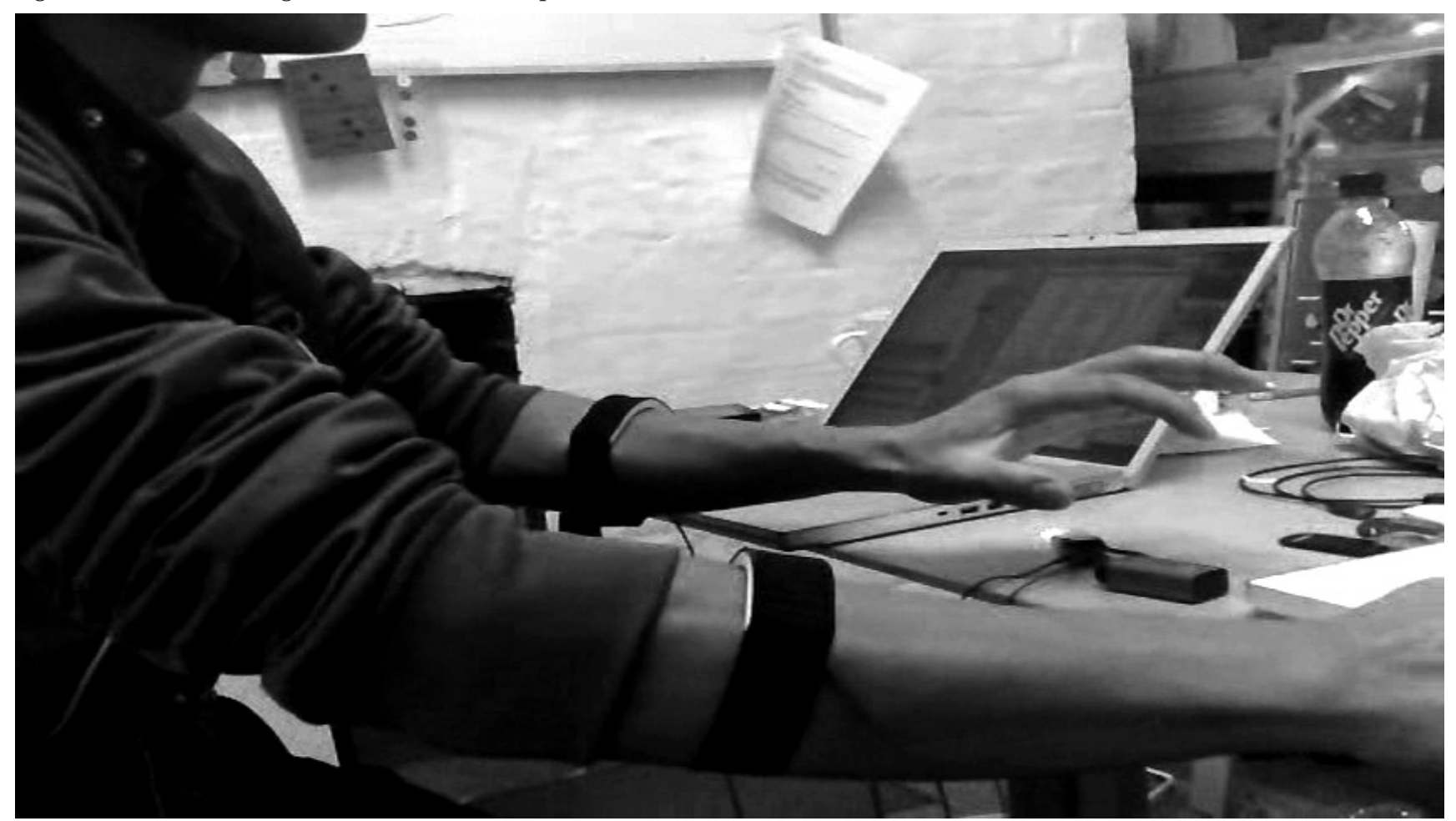




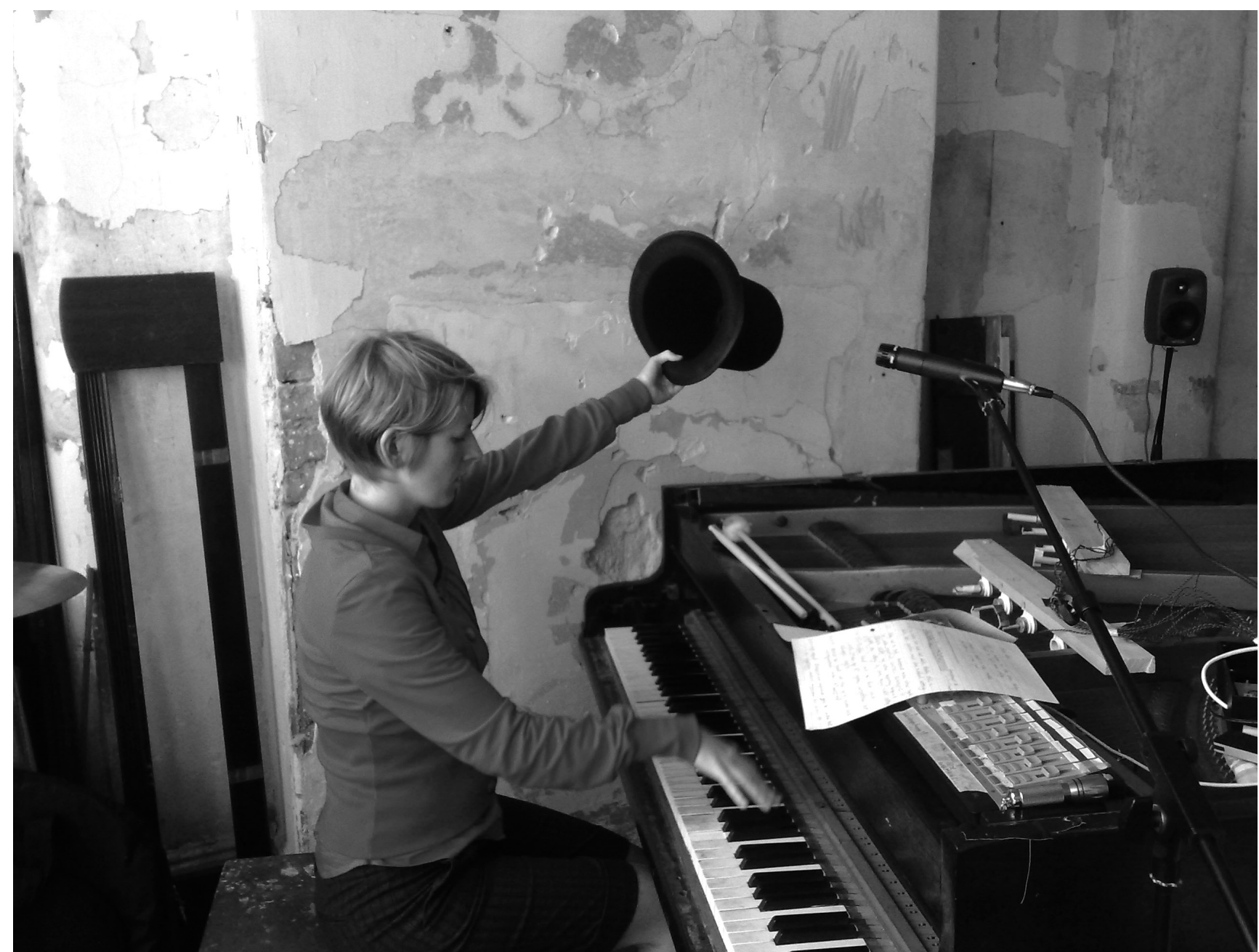

Fig. 4. Practicing for the collaboration with Centre for Digital Music. (Photo $\subset$ Sarah Nicolls)

constantly shifted my attention, and the process thus felt akin to performing with other live musicians. Indeed, the resulting piece I found to be such a detailed web of interactivity, with many subtle changes of technological response, that it felt very much as if I were improvising with Tremblay himself: The "performance environment" engaged me in a living, breathing way. What fascinates me is how strict yet supple the piece is, and I conclude that using improvisation as a methodology enabled this commonality to thrive.

\section{Case Study 3}

Atau Tanaka's Suspensions [18] shows how improvisation was used to generate the grammatical or theatrical language for an interactive system. We used one EMG sensor (reading electrical currents created by muscle contraction) on each arm (on the forearm extensor muscles) (Fig. 3) and a double-axis accelerometer on the right wrist. We set out to create a piece that would combine my natural gestural/physical/emotional approach to the piano-including improvisation in the final performance-with Tanaka's compositional language and detailed and practical knowledge of the sensors. Although we used his physical performance language as a basis for my learning to "play" the sensors (i.e. his gestural shapes and tricks to create the right readings), we allowed room, using improvisation, for my own performative language to develop.

After generating some initial motivic and textural musical ideas through improvisation, I further improvised upon these while wearing the sensors to see what kind of data they would generate. In two or three initial sessions together, I took the sensors and began to understand what they did, by simply making gestures and watching their resultant data in a patch. This soon became too limited, so we made a frame patch with which I could practice using sonic feedback. From this point, I practiced purely with the sensors-using my arms in midair to find the thresholds and to find gestures that produced the right amount of muscle tension and to begin to memorize where and how I needed to be to create useful signals-internalizing the "instrument" of the sensors.

Returning to the piano was difficult after this extended period of learning the sensors. Space here is not sufficient to go into more detail about the process, but after giving a work-in-progress showing to a theater-trained audience I worked to restore the relationship of sensor use to pianistic gesture. The tangent of performing without the piano in a theatrical setting however did give useful insights into meanings attached to gestures and also raised questions about whether or not it was desirable to reveal the technology [19] and how much I wanted the audience to understand the connections between gesture and sound. Again, Tanaka and Knapp serve as useful ends of the spectrum in this case, with Knapp wearing his sensors hidden beneath a suit 


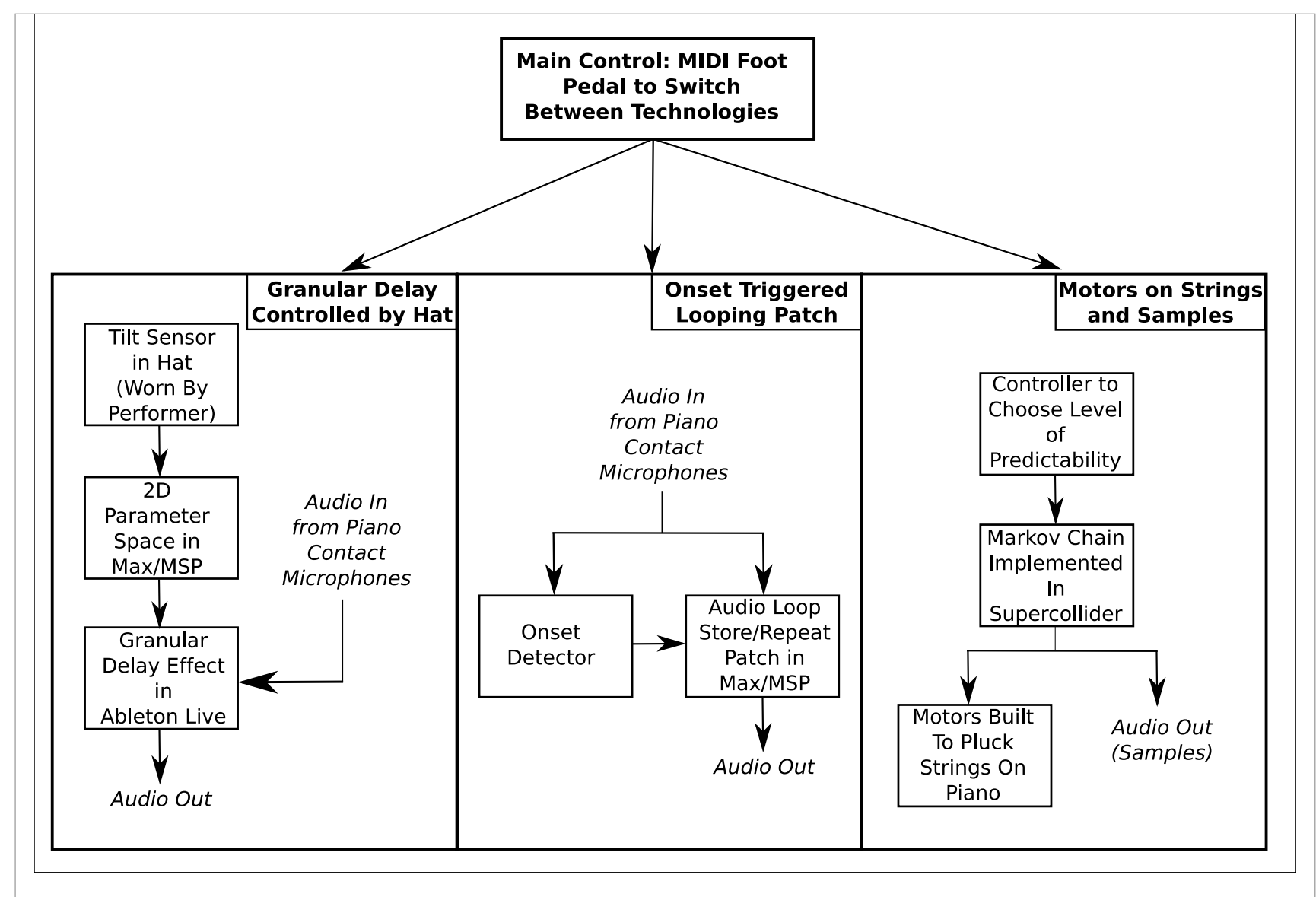

Fig. 5. Schema for Case study 4 resulting piece. ( Adam Stark)

jacket while Tanaka wears his much more openly, almost reveling in them.

For me, the single most successful moment in the proceedings took place when improvising with a sampled chord "in my arm" (i.e. an EMG sensor on my arm was mapped to a sample). I sat at the piano and when approaching the keyboard increased the tension in my arm. I began triggering the very, very beginnings of the sound-much like the sounds of breathing or bowing before a note speaks on a string or wind instrumenthowever, instead of then allowing the actual pitched sound to come out of the computer, I instead played the same chord on the piano. This moment encapsulated for me a genuinely new approach to the piano-one that could only be enabled by this technologycreating a fascinating and intimate space in which to explore the relationships of the sensors to the pianistic performance.

This scenario might never have been realized without improvisation, as it was the combination of Tanaka and his assistant's ideas and computer expertise and my own pianistic approach (again, referring back to earlier descriptions of the internalized imprint of the piano inside my own body) that gave life to this idea. This, I think, is the nub of why improvisation is such a useful tool: It allows the performer to be responsive to the moment, to the environment and to the accidents and discoveries that we intuitively find.

\section{CASE STUdy 4}

In collaborating with the Centre for Digital Music [20] I sought to create an interactive instrumental performance, with flexible performer-computer interaction that would produce live generative computer algorithms and give the player both significant control and room to be surprised by a computer's responses. We hoped to answer some of the challenges discussed as far back as 1973 by Cornock and Edmonds [21], creating a circular performative feedback loop to make the relationship between algorithms and the physicality of the performance seamless and meaningful. We wanted the performer to provide input to generative algorithms-responding to and modify- ing them in real-time-and simultaneously make an engaging spectacle for the audience.

\section{Methodology and \\ Collaborative Process}

For this project, I invented PianoLab: a research space that would allow for realtime, genuinely collaborative, evolutionary research. Crucially, it placed a piano at the heart of the research environment and provided room to build electronics and house several computer stations. As it was the first PianoLab project, its methods of research and implementation were developed as we worked, to solve the balance between what was practical or possible artistically and technically.

The team of four technologists and I worked for an intense week of iterative prototyping. Working in the same room, with ongoing experimentation as part of the development process, we designed, implemented and tested the technologies with active feedback from me. Improvisation formed the bedrock for our research, as the key focus was always how the technology could be used to 
allow the performer to contribute to live algorithms, manipulate the feedback and create an engaging spectacle.

\section{Compositional Process}

In an early brainstorming session we came up with the idea of using a hat to house a Bluetooth triple-axis accelerometer (iCube Gforce 3D-3 v1.1). This would give us an easily identifiable and highly performative input mechanism. I then asked the technologists to show me their current work, to get an idea of what might be possible in the time we had (approximately 2 months to the final performance, with 3 weeks allotted collaborative working time).

The piece evolved as a section-by-section improvisation; I would practice with pre-built systems or patches and suggest ideas that could be created immediately. The use of improvisation was a vital mechanism for me to understand what the pre-existing software systems did and how they might interact with the live, acoustic piano sound. Having decided upon the hat as a major input device, I also wore it while exploring different pianistic textures and simultaneously seeking out a gestural language with my head.

Our final output was a 20-minute work for grand piano, electronic sound and mechanical devices created using a MIDI controller and pedal, nine DC motors and the top hat (Fig. 4) (the performance can be viewed on-line [22]). The piano was placed in the middle of a quadraphonic speaker system, using contact microphones to avoid feedback.

\section{Technology Notes}

The sensors in the hat triggered an algorithm, which we developed to map the tilt of the accelerometer to a 2D parameter space with $x$ and $y$ mapped to the pitch and temporal dispersion parameters of a granular synthesis effect (Fig. 5). For the looping patch, analysis of the spectral range of the live piano audio was used as an onset and offset detector to trigger suitable start and end points for the loop. These loops were continuously stored as indices of an audio buffer with a memory of 1 minute. New onset events triggered the playing of previously recorded loops in a stochastic manner. The system was designed so that the performer would be able to fix the loop being used so that it could provide a repetitive background for further improvisation. The rhythmic patterns used by the motors and piano samples were generated using Markov chains organized by varying degrees of predictability, selectable by the performer using a MIDI controller.

\section{Use of Performance as a Research Method}

Prior to the final performance, we held two pilot performances to further develop the piece, the first of which took place at the end of the first week of collaboration. Limited by the then-current state of the technology, this performance was incredibly informative for us, providing instant feedback.

For the programmers the performance provided the opportunity to assess the usability of the technology in the context of a unified musical piece, observing how well the necessary transitions between elements of the system worked in the pressure of a real-time environment, and whether this integration of technology with musical performance succeeded aesthetically. I made the following crucial discovery: If the technology is already complex, then the actual musical substance can be more direct or simplified without lowering the overall complexity of the artistry.

This question of where complexity resides is also a powerful design point If one desires the gross result to be balanced, then cases where more complexity occurs at the interface level should be balanced by less complexity in the detailed physical control: that is, some-

Fig. 6. First prototype of Nicolls's piano. (Photo $($ C Sarah Nicolls)

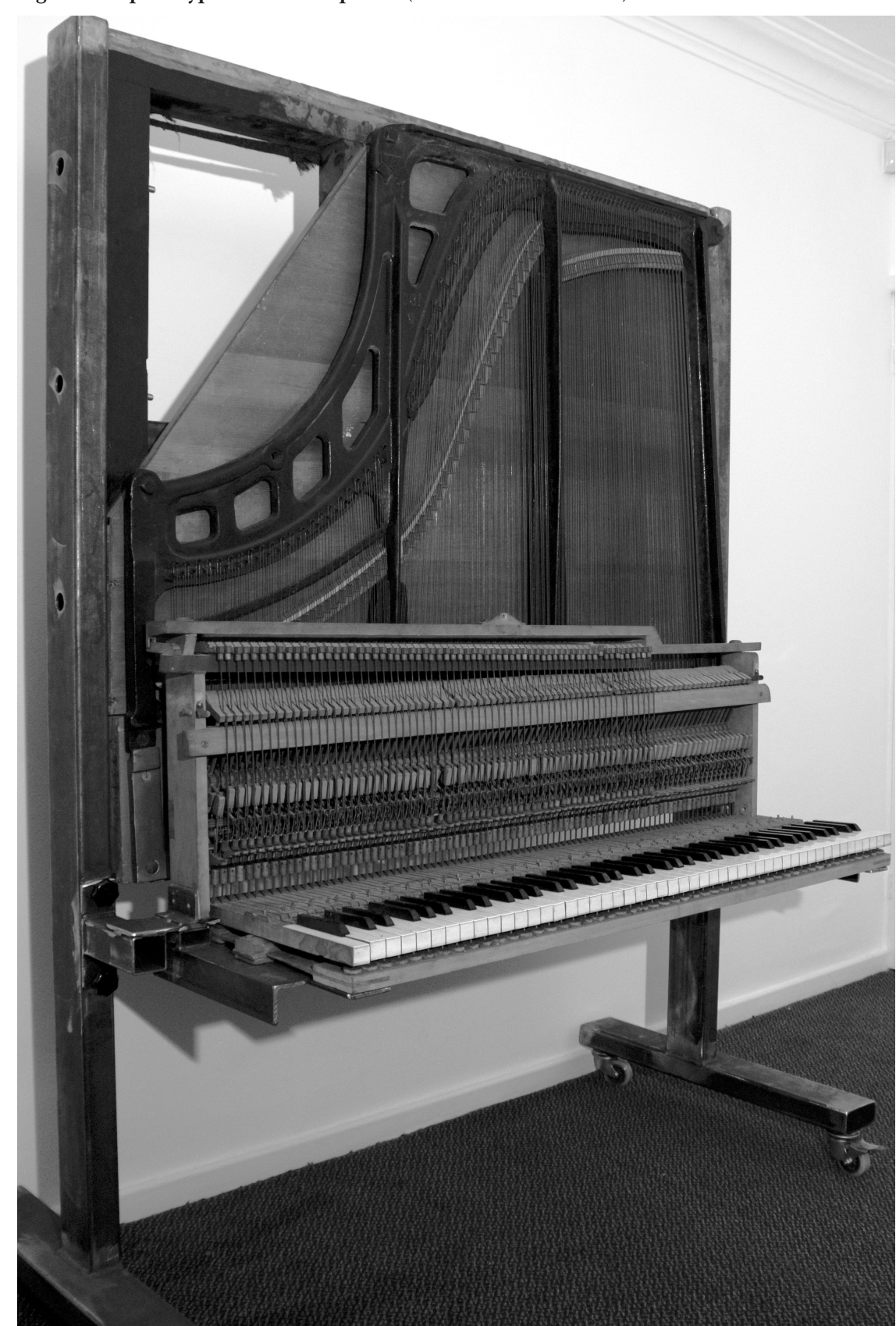


thing with a lot of buttons or faders that need to be used frequently might not be best paired with detailed muscle tension control. Similarly, if balance is sought between predictability and unpredictability, then placing features with results that cannot be predicted in certain "areas" of one's instrument can create useful creative springboards.

I also made discoveries about gestural control of algorithms while playing, in particular related to the advantages of the sensors placed in the hat: They afforded physically communicative control without impinging on or affecting the piano playing itself and thus were easily isolated from the other elements of the music at any point. Feedback from the audience was also immensely valuable and was acted on in the following performance: The sensors used in the first performance were placed in an inconspicuous hat, and we noticed that several audience members did not make the connection between the gestures and the sound manipulations, as they seemed intrinsic to the performance. As a result, the sensors were placed in a top hat for the next performance, which the audience found very straightforward.

\section{Reflections from the Technologist(s)}

The experience of working toward specific artistic goals, as opposed to scientific ones, was both a novel and a rewarding experience. With the focus on workable real-time implementations, while demanding the technology produce a subjectively interesting aesthetic, the process led to extended discussion and large output from all involved. In comparison to work developed in a laboratory, the instant feedback from the pianist allowed quick identification of creative dead ends and forced the focus upon the most interesting ideas, with little misunderstanding. Development "onsite," with the ability to immediately test ideas, led to the elimination of erratic technological behavior and a convergence toward the technologies of the final piece.

\section{Reflections from the Performer}

In developing interactive performance, the complexity of the potential relationships between gesture and sound is much better expressed in real-time demonstration than in remote conversations or, worse, written debate. For choosing the correct input signal, guiding it through a relevant process and producing a meaningful output, I found the laboratory method to be extremely liberating and time-saving.
It was interesting to note the different approaches of artist and scientist in this context-the desire for immediate visible or tangible elements with which to play, measured against a detailed, thorough and quite time-consuming process of making the technology do what we wanted. Michael Zbyszyński [23] made reference to these parallel demands when discussing a similar project with Frances-Marie Uitti at the Center for New Music and Audio Technologies and the need for technologists to work much faster and on-the-fly than would be appropriate for securing technology for an actual performance. In reality, the balance between time in the laboratory and the time apart worked best for technological and musical development.

Some points I had discovered previously were reinforced-for example, that improvising with algorithmic systems can stimulate greater artistic freedom or range. Other discoveries were new; one of the most important of these was about the actual language of music in interactive music. It is a potential equation: If the understanding of the interactivity in the audience's perception lends greater weight to the performative communication, then demonstrative and simply made gestures or musical material can carry the message most effectively.

Overall, the project served to highlight the need for and benefit of this kind of collaborative lab-based work, especially when dealing with interactive technology.

\section{CurRent DeVELopments}

At the time of writing I have begun experimenting with a purely live sampling scenario, where I can grab the sounds I am currently playing by reaching into a particular point in the air above the keyboard and then manipulate these with different gestures. This research is being undertaken with Nick Gillian at the Sonic Arts Research Centre, Belfast, using a Polhemus magnetic tracking device [24]. Setting up PianoLab as a permanent space is a long-term goal, and over the next 3 years we will also be developing further prototypes of the new piano (Fig. 6) [25]. To complete the circle, this itself was the result of improvisation: during the first PianoLab, I dismantled a piano, hanging the soundboard from the ceiling; while it hung there, I began to imagine re-attaching a keyboard to it, to create a new spatial relationship between keyboard and strings.

\section{Acknowledgments}

The HCI:UK 2008 collaboration was made possible by a (re)Actor3 Artist in Residence Commission, sponsored by the Centre for Digital Music, Queen Mary, University of London, and produced by BigDog Interactive Ltd. My initial research into interactivity was funded by the Arts and Humanities Arts Research Council; the development of PianoLab was enabled by a Brunel Research Innovation and Enterprise Fund. I am grateful for further PianoLabs, including those at CNMAT, Newcastle University and the University of Cincinnati, and for input from Pierre Alexandre Tremblay for Case Study 2.

\section{References and Notes}

1. Chikashi Miyama (Angry Sparrow) and Ben Knapp (with Eric Lyon, Gascia Ouzounian), NIME 2009, Concert 2, Friday, 5 June 2009. See <nime2009.org/ concert.pdf> (accessed 28 December 2009).

2. Derek Holzer at noise=noise, Goldsmiths, University of London, 17 February 2009, curated and organized by Ryan Jordan.

3. SSS (Atau Tanaka, Cecile Babiole, Laurent Dailleau), stitched-up, sk-interfaces closing event, FACT (Foundation for Art and Creative Technology), Liverpool, 29 March 2008. See <www.fact.co.uk>.

4. Miyama and Knapp [1].

5. See <o-art.org/history/Computer/CCRMA/ CCRMAres.html> (accessed 28 December 2009).

6. E. Jessop, "The Vocal Augmentation and Manipulation Prosthesis (VAMP): A Conducting-Based Gestural Controller for Vocal Performance," demonstration, NIME Pittsburgh, 2009.

7. J. Richards, "Lost and Found: The Mincer" Leonardo Electronic Almanac 15, Nos. 11-12 (2008). Available at <leoalmanac.org/journal/Vol_15/lea_ v15_n11_12/JRichards.asp >

8. Bob Ostertag, "Human Bodies, Computer Music," Leonardo Music Journal 12 (2002) p. 11.

9. G. Essl and S. O'Modhrain, "Enaction in the Context of Musical Performance," Interdisciplines virtual workshop (by participants in Enactive interfaces Network) (2004) p. 1. Available at <www.interdisciplines. org/enaction/papers/17>.

10. C. Cadoz and M. Wanderley, "Gesture-Music" in M. Battier and M. Wanderley, eds., Trends in Gestural Control of Music (Paris: Editions IRCAM, 2000) pp. 71-93.

11. E. Miranda and M. Wanderley, New Digital Musical Instruments: Control and Interaction beyond the Keyboard (Wisconsin: A-R Editions, 2006) p. 10.

12. Arts and Humanities Research Council project, May-December 2007.

13. Richard Barrett, Adrift, PSI 09.10 CD. Recorded live at The Warehouse, London, 29 November 2007. Available at <www.squidco.com $/ \mathrm{miva} / \mathrm{mer}$ chant.mv? Screen=PROD\&Store_Code $=$ S\& Product_ Code $=12431>$

14. Performances: FURT, Red Rose pub, Finsbury Park, London, spring 2007; and fORCH, Spitalfields Festival, summer 2007. See <furtlogic.com>.

15. See <web.mac.com/sarahnicolls/research/ *Barrett.html>.

16. Richard Barrett, personal e-mail, December 2009.

17. First performance, University of Huddersfield, U.K., 6 March 2009.

18. First performance, Huddersfield Contemporary Music Festival, Huddersfield, U.K., 21 November 2009. See <www.hcmf.co.uk>.

19. Whether to "reveal the magic and do the trick anyway"-Augusto Corrieri summing up our process for Soundwaves Festival $2007<$ web mac.com/ sarahnicolls/research/*Augusto_Corrieri.html>. 
20. Centre for Digital Music at Queen Mary, University of London. See <www.elec.qmul.ac.uk $>$. Click on Research/Centre for Digital Music.

21. S. Cornock and E. Edmonds, "The Creative Process Where the Artist Is Amplified or Superseded by the Computer," Leonardo 6, No. 1 (1973) pp. 11-16.

22. See <web.mac.com/sarahnicolls/research *machines.html

23. M. Zbyszyński, "Augmenting the Cello" (NIME Paris 2006).

24. See experiment at <www.youtube.com watch?v=EA90JC9PUKg $>$
25. Sunday Lunch Club series organized by Prototype Theatre <www.proto-type.org>

\section{Discography}

The piano music of Niccolo Castiglioni on Metier $<$ www. amazon.com/s?ie=UTF8\&field-artist=Niccolo $\% 20$ Castiglioni\&rh=n:5174,p_32:Niccolo\% 20 Castiglioni\&page $=1>$.

Alexander's Annexe Push Door To Exit on WARP Records <http://warp.net/records/releases/ alexanders-annexe/push-door-to-exit $>$.

Richard Barrett's Adrift on psi records <www. emanemdisc.com/psi09.html>
Michael Edwards I kill by proxy on sumtone records $<$ www.sumtone.com/recording.php?id=31>.

Manuscript received 1 January 2010.

Sarah Nicolls is a pianist specializing in contemporary music and live electronics, regularly performing concerti with the London Sinfonietta and featured on BBC Radio 3. Nicolls also plays in Alexander's Annexe (Warp Records). Nicolls is a Senior Lecturer in Music at Brunel University. See also <www. sarahnicolls.com>. 


\section{Leonardo Music Journal 22 (2012) Acoustics}

Immersed as we are in electronically mediated sound, at the end of the day-whether it's coming from ukuleles or earbuds—-sound reaches us through acoustic pressure. The sheer physicality of sound, and its quirky interaction with our sense of hearing, has driven many a composer and sound artist to go back to the "year zero" in music-before the codification of melody, rhythm and harmony-and explore fundamental aspects of the physics and perception of sound.

For Volume 22 of LMJ we solicit articles and artist's statements on the role of acoustics and psychoacoustics in music and audio art.

\section{DEADLINES}

15 October 2011: Rough proposals, queries

1 January 2012: Submission of finished articles

Address inquiries to Nicolas Collins, Editor-in-Chief, at: <ncollins@saic.edu>.

Finished articles should be sent to the LMJ Editorial Office at $<\operatorname{lmj} @$ leonardo.info $>$.

Editorial guidelines and information for authors can be found at <http://leonardo.info/Authors $>$.

Note: LMJ is a peer-reviewed journal. All manuscripts are reviewed by LMJ editors, editorial board members and/or members of the LMJ community prior to acceptance. 